\title{
Identification the Risk Factors of Industry-University-Research Cooperation Based on the Explanatory Structure Model
}

\author{
Ling $\mathrm{LI}^{1, a}$, Peng Guo ${ }^{2, b}$, Wei Zhang ${ }^{3, c}$, Feng Feng ${ }^{4, d}$ \\ Xi'an University of Science and Technology, 58 Yanta Rd, Xi'an, China
}

\author{
302832456@qq.com
}

\begin{abstract}
Key words: Production and research; cooperation and innovation; cooperation risk; explanatory structure model
\end{abstract}

\begin{abstract}
The innovation of industry-university-research cooperation is a technological innovation activity held by enterprises, universities and research institutes according to the principle of "benefit sharing, risk sharing, complementary advantages and common development". While we are aware of its advantages, we also have to know the existing risks, so we can use this cooperation form better. Firstly, based on a large number of literature combing, quantitatively analyze the risks of industry-university-research cooperation, find out the main factors which impact the process and outcome of the industry-university-research cooperation; Secondly, through the main factors which impact the process and outcome of industry-university-research cooperation, establish the measure index of the industry-university-research cooperation. Finally, based on the explanatory structure model, divide the different risk factors, figure out the direct and fundamental factors in the risk of the industry-university-research cooperation, which provides the theoretical basis for the steady and orderly development of production and research.
\end{abstract}

\section{Introduction}

The industry-university-research cooperation is the docking and coupling of synergism and integration which developed by different social division of labor in the function and resource advantages. It is an important way to access each other's heterogeneous resources for the enterprises [1]. Through the cooperative innovation of production and research, which can achieve the sharing, circulation and complementary synergies of resources, broaden the field of technological innovation and shorten the product development cycle [2]. However, there are so many differences between the various cooperation in the organizational structure, cooperation goals and so on, when the cooperative parties take technology research and development, product marketing, knowledge transfer and other social activities and economic activities, there will always have a certain risk in the process of cooperation and innovation, leading to failure of cooperative innovation of production and research. Eva M. Mora - Valenti (1999) analyzes from the perspective of the association and organizational factors influencing the cooperation and innovation of enterprises and research institutions, figure out the cooperation experience of the enterprises and the scientific research institutions, the similarity of partners' technical ability, the loyalty of the partners are main risk factors constituting the cooperation and innovation of enterprise and scientific research institutions [3]. Ji Yihong (1999) pointed out on the basis of field investigation that the unequal distribution of benefits is the main reason to cause the conflict by the current the industry-university-research cooperation in China and put out the solution based on the typical correlation method [4]. Chen Wei (2014) based on the theory of complex network theory, the cooperative innovation of production and research regarded the ocean energy industry as the research object to analyze the structural characteristics of the simulation network, on this basis, the empirical simulation method is used to point out the risk problem of production and research innovation [5]. Wang Jian (2016) based on the phenomenon of information asymmetry in the process of the industry-university-research cooperation, put forward a "gradient" model to prevent the occurrence of risk [6].From the previous text we can see that the relevant scholars have done a lot of research on the risks faced by production-research cooperation, and have made some research 
accomplishment. However, most of the previous studies focus only on a certain point of risk, mostly analyze from a single level and lack of a comprehensive system to explain its influencing factors. Based on this, this paper systematically finds out the risk factors faced by the industry-university-research cooperation, obtain the primary and secondary relations and the hierarchical relations which clearly affect the risk factors of the industry-university-research cooperation with ISM model and explain, which makes the complicated risk of production and research clear and thorough, provide a new perspective to solve the risk of cooperative innovation of production and research.

\section{Risk assessment System for the Industry-university-research Cooperation}

The risk of cooperative innovation of production and research is related to the main body of the industry-university-research cooperation, all parties have their own complex organizational structure. In the process of cooperation, there is a round exchange of material, energy and information in the external environment. Therefore, this article is divided into two dimensions: endogenous risk and exogenous risk [7], the reasons are following: endogenous risk is relative to exogenous risk, it is caused by the enterprise's own business model, internal organizational system, internal staff quality and other factors, the endogenous risk can through the alliance itself to avoid, control and resolve. The exogenous risk is mainly due to the external environment changes and caused by a series of risks, exogenous risk will not be dramatic changes in a certain period of time which has a limited impact to the the industry-university-research cooperation .

2.1 Endogenous Factors Technical risk. The technological innovation of the industry-university-research cooperation has significant complexity and arduousness. The greater the resource input, the greater the risk. If the technology is not stable, the uncertainly technical prospects, the effect and life expectancy will be a risk; if the technology itself is not mature, lack of auxiliary technology or rapid technological change to make the risk of innovation failing at the halfway; if the pursuit of technology feasibility and the production accuracy are inconsistent in the development, the technology into the product process will also have the risk. Therefore, the whole process of cooperative innovation is lurking with varying degrees of technical risk.

Organizational culture risk. Organizational culture refers to the values that can be shared among members of a cooperative organization. If there is a lack of co-existence among the partners, then there may be conflicts between partners in the process of cooperation because of cultural differences [8]. In the cooperation of production and research, each subject has its own unique cultural atmosphere orientation and value demand, so different corporate culture will appear difficult compatibility, the result makes the two sides appearing interest conflict. With the deepening of the contradictions, the trust degree between partners appears cracks, seriously reduce the ability to work together and even make the rupture of cooperation finally.

Knowledge spillover risk. Knowledge spillover risk refers to the possibility that a party's core knowledge or core technology is unilaterally stepped or deliberately leaked by the partner [9]. The industry-university-research cooperation is a cooperative partnership based on the knowledge heterogeneity and unique ability of both parties. If one of the partners want to monopolize or leak of each other's unique heterogeneous resources in the process of cooperation, which will lead to the serious cracks of relationship between partners' trust and the interests damage. In the cooperative innovation system, the advantage of university-research is the integration and innovation of knowledge, business advantage is the production, marketing and management. The university-research doesn't trust the feedback of enterprises interests and tends to overestimate the technological innovation value. Enterprises believe that the development of investment, the scale production, market management's risk creating greater value and tend to depress the value of technology. In addition, the distribution manner of knowledge results, timeliness and other improper choice will have a certain risk.

Moral risk refers to the risk that the subject is subjectively and deliberately violating the implied agreement or unwritten business practices for its own interests and causes the interests' loss of others [10]. Because the goal of the members pursuing is different in the system, the R \& D side is 
committed to technology research and development, the production side is committed to production and management, each parity has their own standards to measure the performance which all tend to consider from their own point of view and stress their own importance, while ignoring to coordinate with other departments. In addition, the university-research declares the R \& D projects beyond their ability in order to get the government and corporations' honor and financial support which all belong to moral risks.

2.2 Exogenous Factors The risk of incomplete development of the industry-university-research cooperation. The industry-university-research cooperation model had been developed in a wide range in western developed countries in 1983. However, due to the lack of understanding and acknowledge, the industry-university-research cooperation is still confined to the narrow relation, low level of cooperation within the scope of cooperation. At present, China's industry-university-research cooperation hasn't realized the real benefit sharing and risk sharing. The degree of university participation is much lower than the foreign developed countries. And enterprises do not spontaneously seek cooperation with universities to solve the risks arising from business development process.

Market risk. Market risk refers to the risk arising from the difficulty in determining market acceptance and time, the difficulty in predicting the rate of diffusion of new technology products, the difficulty in determining market prices and competitiveness, and the difficulty of identifying the right market strategy. In the market economy conditions, heterogeneous resources are configured specifically by the market configuration, product supply and demand controlled by the price mechanism and competition mechanisms, it is difficult to predict. If the market demand changes make $\mathrm{R} \& \mathrm{D}$ products difficult selling in the market, or product market share less than expected target, which all will lead the investment cannot get repaid and produce market risk.

The risk caused by unfulfillment support efforts of government and society. Enterprise R \& D difficulties, risks and substantial compensation cannot really shared by the government and society. Most local governments only support in the form of small amounts of money loan. In reality, according to the risk compensation system of Chinese SME guarantee institutions, the local government subsidizes up as $3 \%-5 \%$ of the registered capital of enterprises each year. The government's risk compensation is far from sufficient for the economic consumption needed to innovate for these small and medium-sized enterprises .

The risk brought by the defective current laws and regulations. China has not yet introduced specifically regulations for the industry-university-research cooperation. "Science Progress Law" proposed to establish specifically corresponding legal documents for the industry-university-research cooperation, but until now also don't carry out the specific operations. Even the "Enforcement Law of The Industry-University-Research Cooperation" does not directly stipulate the possible benefits distribution arising from the industry-university-research cooperation

The risk caused by the unfullfillment development of intermediaries. The continuous and healthy development of industry-university-research cooperation requires the intermediaries with the function of social exchange to communicate information, provide specialized consulting services and coordinate the main interests of production and research. At present, specialized agencies severing for the industry-university-research cooperation account for a small part in the China's formal intermediary agencies, and basically are part-time jobs for other intermediaries, there is almost no independent industry-university-research intermediary.

\section{Analyze the Influencing Risk Factors of Industry-University-Research Cooperation Based on Interpretative Structure Model}

3.1 ISM Model of Industry-university-research Cooperation Risk There are different types of risks in the process of industry-university-research cooperation. It is necessary to clearly understand the risk factors that affect the overall situation if we want to effectively reduce the risks of industry-university-research cooperation. Therefore, this paper introduces the interpretative structure model to explain the importance of risk and targets to solve the risks faced. Through the analysis of causing the risk of industry-university-research cooperation, according to the basic steps 
of ISM technology to carry out multiple correction tests, obtain a reasonable risk assessment of industry-university-research cooperation as shown in Table 1.

\begin{tabular}{|c|l|}
\hline \multicolumn{1}{|c|}{ Assessment element } & \multicolumn{1}{|c|}{ Evaluation of the representative indicators } \\
\hline \multicolumn{1}{|c|}{ Technical risk } & S1: Technology Maturity S2: Technical Feasibility \\
\hline \multicolumn{1}{|c|}{ Knowledge spillover risk } & S3 values S4 culture system \\
\hline \multicolumn{1}{|c|}{ Interest distribution risk } & S5 knowledge sharing mechanism S6 the trust of both sides \\
\hline \multicolumn{1}{|c|}{ Market risk } & S7 Interest distribution mechanism S8 interest balance point \\
\hline $\begin{array}{l}\text { The risk of incomplete development of the } \\
\text { industry-university-research cooperation }\end{array}$ & $\begin{array}{l}\text { S9 the pursuit of the target S10 the Normative degree of } \\
\text { industry-university-research }\end{array}$ \\
\hline \multicolumn{1}{|c|}{$\begin{array}{l}\text { S11Cooperative Mode and Development Degree of } \\
\text { industry-university-research }\end{array}$} \\
\hline $\begin{array}{l}\text { The risk caused by unfulfillment support efforts of } \\
\text { government and society }\end{array}$ & S12marketsize and prospects S13changes in market demand \\
\hline $\begin{array}{l}\text { The risk brought by the defective current laws and } \\
\text { regulations }\end{array}$ & $\begin{array}{l}\text { S15 Thernment support efforts } \\
\text { industry-university-research }\end{array}$ \\
\hline $\begin{array}{l}\text { The risk caused by the unfullfillment development of } \\
\text { intermediaries }\end{array}$ & S16 The perfection of intermediaries \\
\hline
\end{tabular}

3.2 Determine the Correlation Between the Various Factors The 16 elements in the system interact with each other, and this relationship is represented by a matrix, ie, the adjacency matrix (A) (see Table 2). Matrix represents the provisions, the system elements $\mathrm{Si}$ affect $\mathrm{Sj}$, the matrix element aij as 1 ; when system elements $\mathrm{Si}$ doesn't affect $\mathrm{Sj}$, the matrix element aij as 0 , that is,

\section{Aij $\left\{\begin{array}{l}1 \text { When Si has an effect on } \mathrm{Sj} \\ 0 \text { When Si has no effect on } \mathrm{Sj}\end{array}\right.$}

The adjacency matrix $\mathrm{A}$ is established according to the factor relation. In the matrix operation, that is, the matrix A + I, take the power arithmetic of the matrix A + I until the equation (1) is satisfied and obtain a positive integer $n$. The matrix $M=(A+I) n$, whose element mij is 1 represents the existence of some transitive relationship between the element $\mathrm{Si}$ and the element $\mathrm{Sj}$. The exponentiation of the Boolean algebra is performed for the matrix $A+I$, and $M=(A+I) 8=(A$ $+\mathrm{I}) 9$ is obtained. That is: $\mathrm{M}=(\mathrm{A}+\mathrm{I}) 8=$

\begin{tabular}{|c|c|c|c|c|c|c|c|c|c|c|c|c|c|c|c|}
\hline 1 & 1 & 0 & 0 & 1 & 0 & 0 & 0 & 0 & 0 & 1 & 1 & 1 & 7 & 7 & 1 \\
\hline 1 & 1 & 0 & 0 & 1 & 0 & 0 & 0 & 0 & 0 & 1 & 1 & 1 & 1 & 1 & 1 \\
\hline 1 & 1 & 1 & 1 & 1 & 1 & 1 & 1 & 1 & 1 & 1 & 1 & 1 & 1 & 1 & 1 \\
\hline 1 & 1 & 1 & 1 & 1 & 1 & 1 & 1 & 1 & 1 & 1 & 1 & 1 & 1 & 1 & 1 \\
\hline 0 & 0 & 0 & 10 & 1 & 0 & 0 & 0 & 0 & 0 & 0 & 0 & 0 & 0 & 0 & 0 \\
\hline 1 & 1 & 1 & 1 & 1 & 1 & 1 & 1 & 1 & 1 & 1 & 1 & 1 & 1 & 1 & 1 \\
\hline 1 & 1 & 7 & 1 & 1 & 1 & 1 & 1 & 7 & 1 & 1 & 1 & 1 & 7 & 7 & 1 \\
\hline 1 & 1 & 7 & 1 & 1 & 1 & 1 & 1 & 7 & 1 & 1 & 1 & 1 & 7 & 1 & 1 \\
\hline 1 & 1 & 1 & 1 & 1 & 1 & 1 & 1 & 7 & 1 & 1 & 1 & 1 & 7 & 1 & 1 \\
\hline 1 & 1 & 7 & 1 & 1 & 1 & 1 & 1 & 7 & 1 & 1 & 1 & 1 & 7 & 7 & 1 \\
\hline 1 & 1 & 0 & $D$ & 1 & 0 & 0 & 0 & 0 & 0 & 1 & 1 & 1 & 7 & 1 & 1 \\
\hline 1 & 1 & 0 & 0 & 1 & 0 & 0 & 0 & 0 & 0 & 1 & 1 & 1 & 1 & 1 & 1 \\
\hline 1 & 1 & 0 & 0 & 1 & 0 & 0 & 0 & 0 & 0 & 1 & 1 & 1 & 1 & 1 & 1 \\
\hline 1 & 1 & 0 & 0 & 1 & 0 & 0 & 0 & 0 & 0 & 1 & 1 & 1 & 1 & 1 & 1 \\
\hline 1 & 1 & 0 & 0 & 1 & 0 & 0 & 0 & 0 & 0 & 1 & 1 & 1 & 1 & 1 & 1 \\
\hline 1 & 1 & 0 & 0 & 1 & 0 & 0 & 0 & 0 & 0 & 1 & 1 & 1 & 1 & 1 & 1 \\
\hline
\end{tabular}

cooperation $\mathrm{R}(\mathrm{Si})$, the first set $\mathrm{A}(\mathrm{Si})$ and the common set $\mathrm{C}(\mathrm{Si})$ of each factor are listed according to the reachable matrix, Firstly find the most advanced factors of the first level, remove the most advanced factor ranks from the $\mathrm{M}$ and so on, until find the most advanced factors of each level. And then according to the recurrence of the binary relationship at all levels, you can get the explainary structural model. 


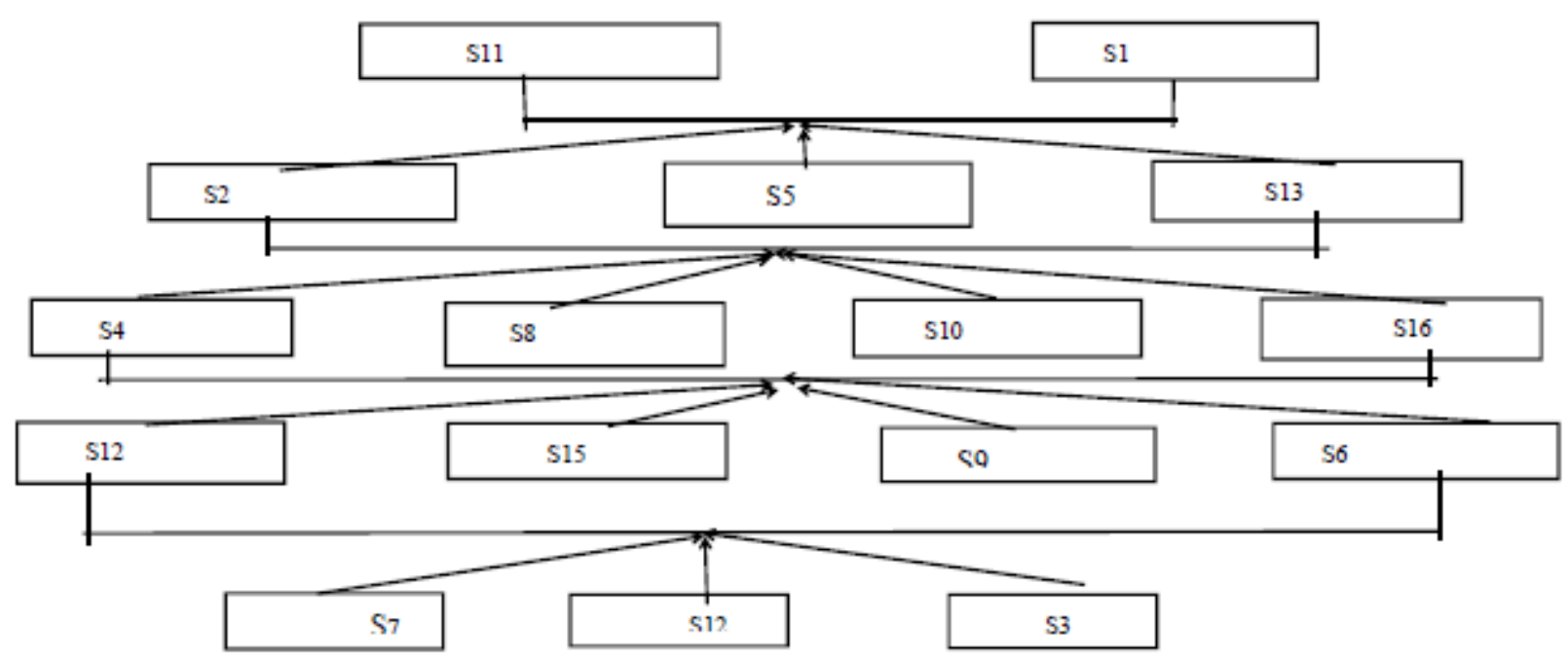

From ISM can be drawn the most direct and most likely to produce risk factors is the maturity of development and industry technology of industry-university-research. So the government should set up special funds to guide the research and innovation of industry-university-research. On the one hand it can increase the motivation of enterprises to participate the innovation while reducing the risk of technological innovation alone; on the other hand it can greatly reduce the lack of funds and affect the industry-university-research cooperation. This will inspire more enterprises, universities to involve in industry-university-research cooperation.

Based on the conclusion of the impact of global risk factors, firstly, the risk should be taken to resolve, share, transfer measures to be controlled. Through a reasonable assessment of technical value, allow intellectual shares and increase the technical holdings and other coordination manners of benefits distribution, so the industry-university-research can share the risk of interest. Secondly, take a systematic assessment to the market demand, market share, competition situation and after-sell service's hard level to effectively avoid the risk. Work with intermediaries, use its rich market information to help with defusing the risk. Use adequate market research and accurate assessment to avoid risks. As the core demand of cooperative innovation, the absorptive capacity and cooperative behavior have a direct influence on the innovation performance of industry-university-research. Therefore, enterprises should play a leading role in shaping the core values.

\section{Conclusion}

In this paper, ISM model is used to systematically analyze the risk factors of industry-university-research cooperation, and provide a new analysis tool for risk management. Through the establishment of multi-level hierarchical model, intuitively reveal the relationship between multiple risk factors, so the managers can clearly find the basic causes and important factors influencing the success and failure of cooperation, which maximally avoid the risk and improve management efficiency in the process of cooperation.

\section{Acknowledgement}

This paper Supported by Educational Commission of Shaanxi Province of China (Grant No. 14JK1446); Specialized Research Fund for the Doctoral Program of Higher Education (Grant No. 2015QDJ081) ; The Foundation of Shaanxi Educational Committee (Grant No. 2013JK0182); the Research Fund for soft science of Shaanxi(Grant No. 2014KRM37-02)

\section{References}

[1] Fan Xia, Zhao Danping, He Yue.Enterprise innovation efficiencies of university-industry 
cooperation and their influential factors science research management [J]. Science and Research Management, 2012,(02):33-39.

[2] Liu Wei, Fan Xia, Wu Jin. Study on the factors that affect the proneness of university-industry cooperation for enterprises [J]. Journal of Management

[3] LIONEL NESTA, VINCENT MANGEMATIN. The dynamics of inno-vation networks [J]. Science Technology Policy Research, 2004(4): $17-28$

[4] Zhu Xiangyu, He Haiyan, Song Xibo. Study on profit distribution in Chinese industry-university-research institute cooperation [J]. Modern Management Science, 20

[5] Chen Wei, Zhou Wen, Lang Yifu, Yang Shaoli. Research of structure and risk in industry-university-research institute cooperation-take ocean energy as example [J]. Science of science and management of S.\&T. 2014,(09):59-66.

[6] Wang Jian, Yuan Jingyang, Hong Zhaobin.Establishment and cultivation of 'gradient' model in diminishing the information asymmetry of industry-university-research institute cooperation [J]. The Journal of Chifeng University (natural science edition), 2016,(18):204-207.

[7] Dai Bin, Wu Mei, Peng Shuang. Research on risk management system for industry-university-research institute cooperative research science and technology management research [J]. Research of Technology Management, 2014,(13):62-65.

[8] Fan Yun, Shao Fang, Zhang Yi. Differentiation-perspective Based Study on the Impact of Organizational Culture Sociability and Solidarity on Organizational Change [J], Management Review, 2011,(08):152-161.

[9] Chen Linbo. Benefit Allocation and Intellectual Property Risk Assessment of Dynamic Alliance in Cumulative Innovation [D]. Chongqing University, 2007.

[10] Ren Duanyang, Song Wei, Gao Xiao Pei. Intellectual property rights distribution mechanism in collaborative innovation [J]. Chinese University Technology Transfer,2016,(Z1):44-45. 